\title{
Impact of Virtual Disaster Collaboration Exercises on Disaster Leadership at Hospitals in Saudi Arabia
}

\author{
Mohammed Ali Salem Sultan ${ }^{1,2}$ - Amir Khorram-Manesh ${ }^{3,4,5}$ • Eric Carlström ${ }^{2,5,6}$ • \\ Johan Berlin ${ }^{7} \cdot$ Jarle Løwe Sørensen ${ }^{6}$
}

Accepted: 13 October 2021/Published online: 2 November 2021

(C) The Author(s) 2021

\begin{abstract}
This study measured the impact of virtual threelevel collaboration (3LC) exercises on participants' perceived levels of collaboration, learning, and utility (CLU) at hospitals in the southern region of Saudi Arabia. Our 3LC exercise is a tabletop training tool used to facilitate disaster education and document CLU. This model enables the practitioner to acquire new knowledge and promotes active learning. An English version of the CLU scale, the validated Swedish survey tool, was applied to 100 healthcare managers or leaders in various positions at both the operational and tactical levels after conducting the 3LC exercises. The response rate was $100 \%$, although not all questions were answered in some cases. The results show that most participants strongly agreed that the exercises focused on collaboration $\left(r^{2}=0.767\right)$ and that they had
\end{abstract}

Mohammed Ali Salem Sultan

mohammed.sultan@gu.se

1 Healthcare Transformation, Model of Care, Regional Health Directorate, Najran 66255, Saudi Arabia

2 Institute of Health and Care Sciences, Sahlgrenska Academy, Gothenburg University, 40530 Gothenburg, Sweden

3 Institute of Clinical Sciences, Sahlgrenska Academy, Gothenburg University, 40530 Gothenburg, Sweden

4 Department of Research and Development, Swedish Armed Forces Centre for Defence Medicine, 42676 Gothenburg, Sweden

5 Gothenburg Emergency Medicine Research Group (GEMREG), Sahlgrenska Academy, 41345 Gothenburg, Sweden

6 USN School of Business, Campus Vestfold, University of South-Eastern Norway, 3603 Kongsberg, Norway

7 Department of Social and Behavioural Studies, University West, 46186 Trolhättan, Sweden acquired new knowledge during the exercises. There was a statistically significant association between participation in the collaboration exercises and perceived learning $\left(r^{2}=\right.$ $0.793)$, as well as between perceived learning and utility $\left(r^{2}\right.$ $=0.811$ ). The collaboration exercises enhance the perceived effects of CLU. They also improve the ability of participants to adapt situational strategies to achieve a safer society. Although exercises were conducted virtually, they were well received by the participants and achieved a value $\mathrm{M}=4.4 \mathrm{CLU}$ score, which opens up new dimensions in collaboration simulation exercises.

Keywords Collaboration exercises · Disaster education - Emergency management $\cdot$ Healthcare personnel training · Saudi Arabia

\section{Introduction}

Increasing numbers of disasters and public health emergencies have resulted in individual and material damages, deaths, and disabilities (Oktari et al. 2020). The majority of these negative outcomes are preventable through enhanced emergency system readiness (Coppola 2006; Carter 2008; Torani et al. 2019). The immediate and appropriate response to such emergencies requires individual and organizational mitigation and preparedness, collaboration and coordinating abilities, communication skills, global awareness, and mutual situational awareness. These elements create bridges spanning multiagency borders and utilize all components of surge capacity, that is, staff, supplies, structures, and systems, to achieve a smooth and adequate transfer and medical management of victims to and within medical facilities (Sagun et al. 2009; KhorramManesh 2020). It is evident that actions, structures, and 
systems implemented within this multiagency approach to disasters and public health emergencies should be harmonized to avoid unnecessary time- and resource-consuming discussions and shortcomings (Boin and 't Hart 2010).

An appropriate level of preparedness may be achieved through either exposure to disasters or proper educational programs (WHO 2017). In addition, readiness to respond to an emergency requires theoretical and practical knowledge (Khorram-Manesh et al. 2015). Sultan, Khorram-Manesh et al. (2020) have indicated that healthcare workers who avoid taking part in emergency management often lack the practical element of readiness. In contrast, knowledgeable healthcare staff seems to have more confidence to act and are more willing to participate in unexpected situations.

Exercises can increase the knowledge and confidence of staff while allowing them to practice in an environment without risk of harm to patients (Andersson et al. 2014; Khorram-Manesh, Lupesco et al. 2016). Various types of exercises exist, including real-time, full-scale exercises with high costs and insufficient training in whole chains of action; three-level collaboration (3LC) and tabletop exercises; and more sophisticated simulation training, such as the medical response to major incidents (MRMI) (Khorram-Manesh, Berlin et al. 2016). There are pros and cons to each of these methods; however, training staff should not only provide opportunities for learning and skill development, but should also include training in multiagency collaboration and coordination in an environment that allows for mistakes and correction (Klabbers 1999; Berlin and Carlström 2008a). Such a model enables the transfer of new knowledge into practice and promotes active learning, which can be innovative and applicable to real life (Revell and Wainwright 2009; WHO 2021).

Some of the aforementioned exercises have a more distinct focus on collaboration, interagency participation, and joint decision making - for example, 3LC and MRMI, which are both validated (Charman 2013; Khorram-Manesh, Lupesco et al. 2016). The former requires only simple instruments and a relatively small space, while the latter uses more sophisticated instruments and requires more space. Both models aim to develop synchronous collaboration and strengthen perceived levels of learning and utility by focusing on flexibility, improvisation, and joint evaluations. The primary target of the $3 \mathrm{LC}$ model is the collaborative elements in mutual tasks; this model aims to reduce organizational barriers (Khorram-Manesh, Berlin et al. 2016). The MRMI targets individual decision making but also delves deeper into the medical perspectives of the management process (Roud and Gausdal 2019).

Collaborative learning in this study is limited to Stein's (1997) and Klabber's (1999) perspectives concerning the learning methods of institutions and, subsequently, the differences between first- and second-order learning. In first-order learning, the participants cannot transfer their new knowledge into practice, either because they are structurally unable or unwilling to do so. In contrast, in second-order learning, the participants acquire new knowledge and apply that knowledge in real-life situations. Collaboration exercises frequently motivate individuals to obtain new skills and professional knowledge from each other (Berlin and Carlström 2011) and support processes that encourage collaboration (Berlin and Carlström 2008a). Participants prefer familiar standardized working patterns, and so participating in collaboration exercises can result in the integration of useful theoretical structures and practices into the work environment (Berlin and Carlström 2008a).

Scientifically verified and well-established exercise models can be used in the context of disaster-prone areas to facilitate disaster education and document collaboration success, learning, and usefulness. The Kingdom of Saudi Arabia (KSA) is a disaster-prone area in need of disaster education (Sultan, Sørensen et al. 2020). In a recent study carried out in the KSA (Al Thobaity et al. 2019), participating doctors and nurses from eight hospitals reported that disaster plans must include five necessary components, namely surge capacity, security, decontamination, communication, and survivor support. These components could strengthen hospitals' preparedness for disaster response and recovery. In another study (Mani et al. 2020), a systematic scoping review focused on armed conflict areas and included a number of common disaster core competency domains, such as disaster planning, communication, safety, chemical, biological, radiological, nuclear and explosive and personal protective equipment (PPE) that could be enhance by workplace education and drills for hospital and healthcare providers.

Nevertheless, there is often a lack of collaboration in the interagency approach to a disaster and an appropriate educational tool is needed to strengthen interagency and intra-organizational partnership and to optimize preparedness. Such demands might be met by 3LC and MRMI simulation exercises, which facilitate follow-up and development evaluation. In particular, 3LC, which has more precise requirements and focuses on organizational attitudes, may be implemented in both central and remote areas of the country.

The current COVID-19 pandemic has been associated with many changes in global perspectives and especially in the development of new digital initiatives (Budd et al. 2020). One such area of development has been virtual learning and education, which has seen rapid growth and popularity as people's attitudes towards technology and ease of access have shifted, making it easier for students to continue their education in different and difficult circumstances (Spiceland and Hawkins 2002; Sahu 2020). This massive unplanned shift from traditional learning to online 
learning has changed the methods used by medical institutions to offer their courses to students (Schwartzstein and Roberts 2017). Our study attempts to measure the impact of virtual 3LC course exercises on participants' perceived levels of collaboration, learning, and utility (CLU) in a hospital context.

\section{Materials and Methods}

This study employed a quantitative research method that employs a survey design to assess the intervention of a formalized exercise model promoting the learning and usefulness of three-level collaboration (3LC) in a Saudi Ministry of Health (MOH) hospital context.

\subsection{Instrument}

This study applied an English version of the Collaboration, Learning, and Utility (CLU) Scale. The CLU-Scale is a validated Swedish survey tool specially designed to measure exercise participants' perceived levels of collaboration, learning, and utility. A CLU survey was developed in different stages by experts in the accidents and disasters field. It was formulated on theories that distinguish between sequential, parallel, and synchronous collaboration (Berlin and Carlström 2008b); learning theories derived from Stein and Klabbers' perspectives on how institutions learn; and the differences in learning orders between the first and second learning orders (Stein 1997; Klabbers 1999). A comparison can be made between collaboration exercises as similar studies have applied the CLU tool (Berlin and Carlström 2015; Sørensen et al. 2018, 2020). Our survey was comprised of 22 items distributed between two sections: a demographic section consisting of 5 items and an evaluation section composed of 17 items across three dimensions-collaboration (C), learning (L), and utility (U)-displayed in Table 1 . The $\mathrm{C}$ dimension evaluated the perceived collaboration characteristics, the $\mathrm{L}$ dimension confirmed collaboration-related lessons, and the $\mathrm{U}$ dimension addressed the transfer of value to real-life scenarios. The CLU scale captured the participants' perceptions based on a 5-point Likert scale ranging from 1 (strongly disagree) to 5 (strongly agree).

\subsection{Setting}

The study data were collected after conducting the $3 \mathrm{LC}$ exercises over three days in October and November 2020, from $10 \mathrm{MOH}$ hospitals, at the Simulation and Skills Development Centre of the Regional Health Directorate in Najran, KSA. Najran region is located in the southern part of the KSA, which is exposed to the potential risk of disasters such as sandstorm, flash floods in wadis, building collapse, and armed conflict at the border.

\subsection{Population and Sample}

The study participants were healthcare leaders working at $10 \mathrm{MOH}$ hospitals in the Najran region, KSA. Participants included staff in various positions at both the operational and tactical levels, namely, hospital director, medical director, nursing director, emergency and disaster director, public health director, financial director, and support services director. The sample size was set at $n=100$ healthcare managers/leaders based on the power calculation (Raosoft 2004), assuming $4.5 \%$ precision with $50 \%$ prevalence and in total population size of 124 with a $95 \%$ confidence interval specified limits.

\subsection{Data Collection and Procedures}

Due to the COVID-19 pandemic, which forced most countries' airports to shut down, lengthy meetings were held through virtual communication between the experts from Sweden and Norway as well as health practitioners with experience in disaster management from Saudi Arabia, in order to teach, train, and prepare them on the course scenarios. In addition, the first course was held through virtual communication between experts and participants, with five qualified health care leaders receiving training from the experts in order to provide leadership on the ground and conduct the remainder of the 3LC course.

The theoretical lectures were presented to those enrolled in the 3LC exercise courses (Figs. 1, 2). Afterward, the participants were divided among four tables, with a leader, a physician, a nurse, and a support services worker at each table. Participants received the necessary instructions to engage in side-by-side tabletop exercise work in two simulated reality. The two case scenarios are:

(1) Scenario one (critical care evacuation within a hospital): a healthcare team is working at a Critical Care Unit and has 10 patients, 30-50 years old. There are three categories: 3 respiratory cases, parenteral nutrition, extensive injuries; 3 cases of severe injuries, intravenous infusion and receiving inotropic medication (they are awake and have spontaneous breathing); and 4 cases have newly undergone surgery due to trauma or heart disease (they are awake, have spontaneous breathing and are mobilized to wheelchair). The event: an alert from hospital management that explosives are located at the main building of the hospital and the critical care unit is threatened. It is impossible to move or disarm the explosives within the next $2-3$ hours. There is an 
Table 1 The collaboration, learning, and utility scale (CLU-scale)

\begin{tabular}{ll}
\hline Dimensions & Items \\
\hline C & The exercises were focused on collaboration \\
C & Sufficient forms of discussion were provided \\
C & There were opportunities to improvise \\
C & Personnel in need of exercise participated \\
C & I performed well-known activities \\
C & Collaboration was initiated immediately \\
C & Clear instructions for collaboration were presented \\
C & My points of view were regarded \\
L & I learned new things during the exercise \\
L & I learned about others' organizational aspects \\
L & I learned about others' communication patterns \\
L & I learned about others' prioritizing of activities \\
L & I learned others' concepts and abbreviations \\
U & Based on what I learned, the exercises were useful to real-life activities \\
U & Based on what I learned, the exercises were useful to command officers \\
U & Based on what I learned, the exercises were useful to ordinary operative staff \\
U & Based on what I learned, the experiences from the exercises impact my daily work \\
\hline Dim
\end{tabular}

Dimensions: $C$ collaboration, $L$ learning, $U$ usefulness

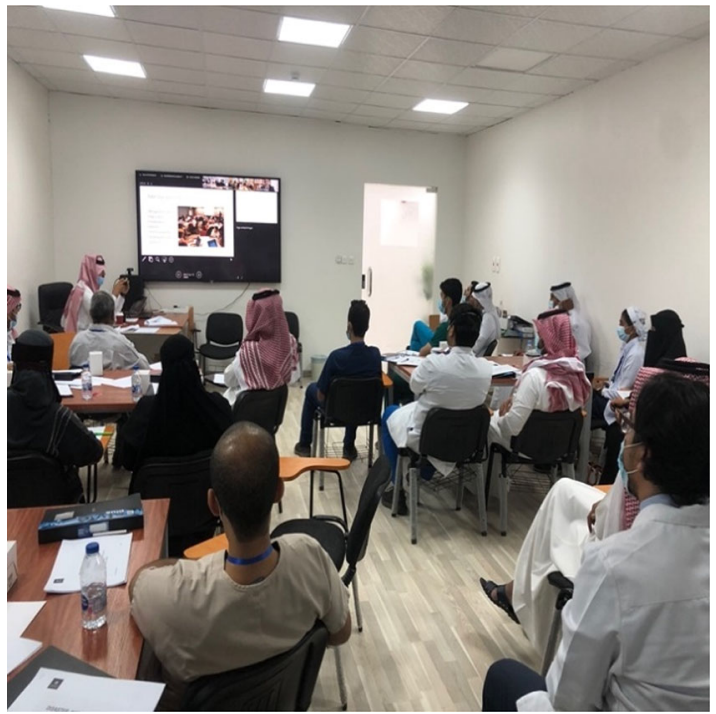

Fig. 1 Theoretical lectures from the Saudi side. Photograph by M. Sultan, Najran, 13 October 2020

immediate need to evacuate patients and staff to clear hospital buildings nearby. Elevators are impossible to use because of suspected triggers and explosives. Support from external staff is not expected. Patients need to be moved 5-6 floors down by the stairs. Evacuation has to start as soon as possible. The healthcare team must report to the hospital management within 15 minutes on strategy, priorities, risk analysis, and possible losses.

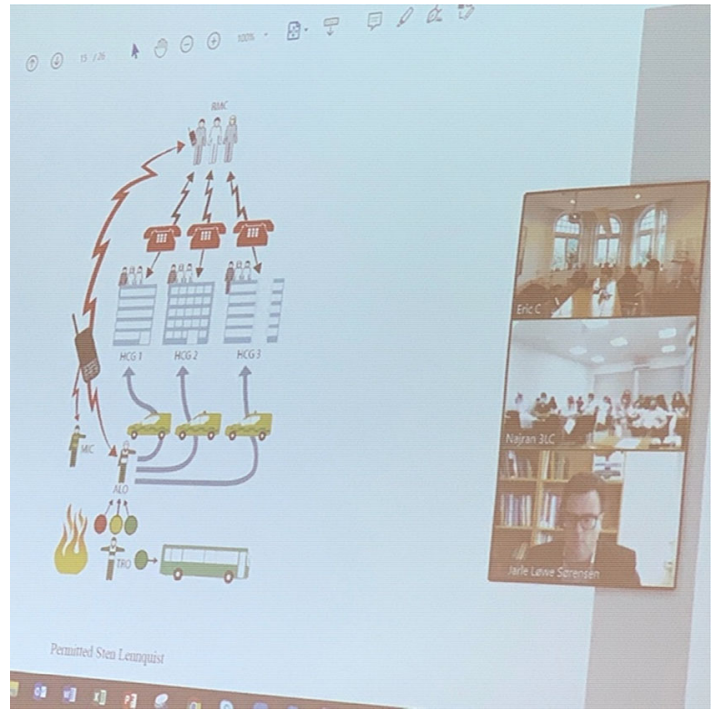

Fig. 2 Theoretical lectures from the Swedish side. Photograph by J. Berlin, Gothenburg, 13 October 2020

(2) Scenario two (mass casualty scenario): a healthcare team is sent from the hospital to a disaster site in the vicinity of the hospital. The event: a post-Ramadan festival is going on, and there are reports of shooting in the area from automatic weapons directed at the crowd. Before your team leaves the hospital, you are informed of casualties-around 100 people are dead and wounded. More teams are prepared, but your team is first in line. The police department and the 
military have secured the area and captured terrorists. About 10 ambulances arrive at the same time as you arrive at the site. The area, a park in the town, is roped off from the public by the police. There are about 75 wounded and dead, all in lying or sitting position. How do you act? You are supposed to give a report to the hospital management as soon as possible.

During each scenario exercise, the exercise leaders measured the time (Fig. 3) elapsed from the presentation of the scenario. After completing the specified allowed time for working on the scenario, each team showed how it individually handled the event (Fig. 4). The exercise leaders then provided the participants with a quick review of the scenario. After that, participants at each table were asked to identify what they could have done differently.

At the end of the course, online CLU survey instruments were sent separately to each participant's email ( $n=100$; online form) hosted on the 3LC platform.

\subsection{Data Analysis}

The homogeneity of the items in the subscales of the CLU survey was analyzed by calculating Cronbach's alpha using the Statistical Package for the Social Sciences (SPSS) version 20. Cronbach's alpha was 0.987, which shows high internal consistency and, according to Brace et al. (2006), is considered satisfactory. The authors used regression analysis to identify independent variables significantly associated with the dependent variable. All significant variables found in bivariate regression analysis were included in the multivariate regression analysis.

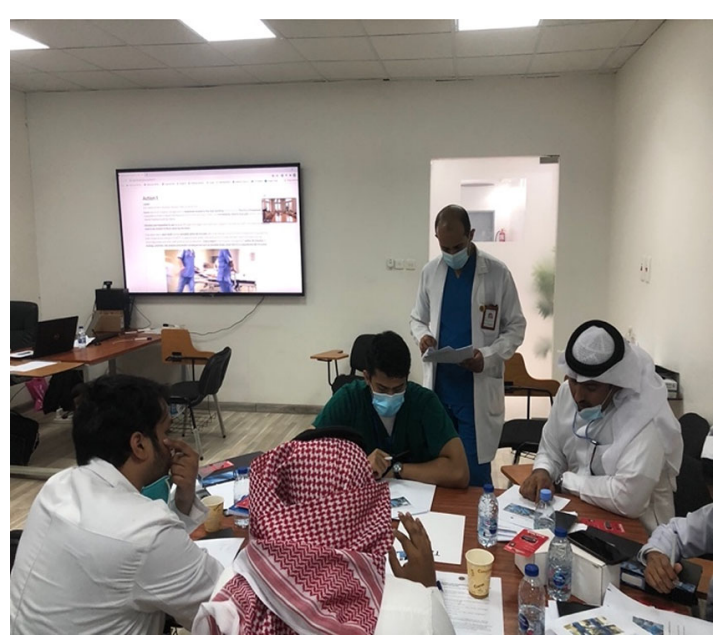

Fig. 3 Exercise leaders count the time while the participants are working on scenarios. Photograph by M. Sultan, Najran, 13 October 2020

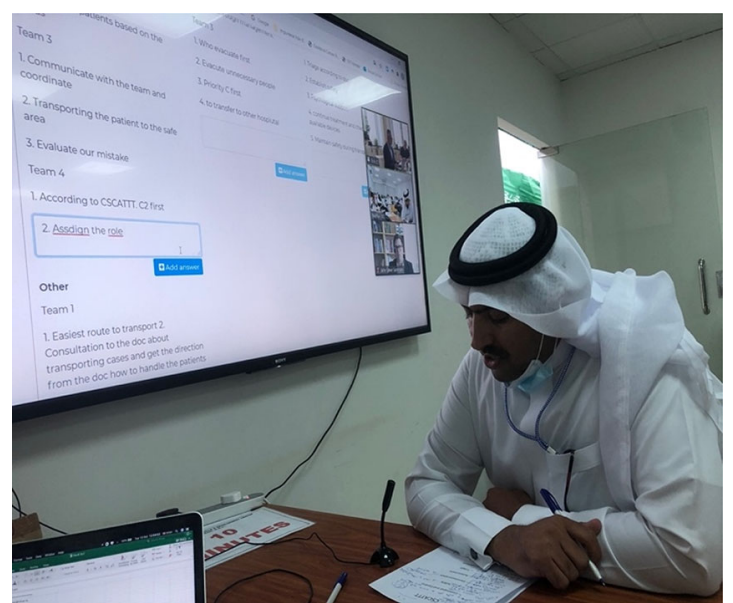

Fig. 4 One of the participants (a team leader) presents the SwedishNorwegian experts his team skills in handling the event. Photograph by M. Sultan, Najran, 13 October 2020

\subsection{Ethics}

Informed consent was obtained from all study participants. They were informed regarding their voluntary participation and the possibility of withdrawing from the study whenever they choose to, with no consequences. Collected data were stored at the research center in each hospital. The information provided was subject only to research purposes, all data were handled confidentially, and the researchers could not disclose the respondents' identities at any time, no matter the circumstance. An ethical committee certificate of approval for the study was obtained from the Institutional Review Board at the Regional Health Directorate in the Najran region (IRB Log Number 2021-19 E; date of approval: 7 April 2021).

\section{Results}

The results have shown various proportions according to the collaboration, learning, and utility dimensions of the used scale. Bivariate and multivariate regressions were used to identify the associated independent and dependent variables.

\subsection{Demographics}

One hundred participants took part in the survey $(n=100)$, of which $37 \%$ were females, and $63 \%$ were males. The overall response rate was $100 \%$, that is, all participants replied to the survey. However, some of the participants did not answer all questions. Consequently, questions with missing answers were categorized as a negative response (Total disagreement), and included in the results. 
Respondents younger than 23 and older than 59 were the least represented. Only $5 \%$ of participants were below age 25 , and $5 \%$ were older than 50 . The mean age group was 29-38 and was the age group that was most represented by the respondents (52\%). About $37 \%$ of the respondents were in the nursing department. Experience ranged from 5 years and less to more than 25 years. Only $4 \%$ of the staff had more than 25 years of experience. Most workers had 5-9 years of experience $(30 \%)$.

\subsection{Collaboration}

A total of $61 \%$ of the participants strongly agreed that the exercise focused on collaboration, while $24 \%$ mildly agreed. Only $7 \%$ disagreed that the exercise focused on collaboration, with the mean $\mathrm{M}=4.34$, and standard deviation $\mathrm{SD}=1.056$. About $88 \%$ either strongly or mildly agreed that acceptable forms of discussion were provided in the exercise. Only $2 \%$ mildly disagreed with the statement, and 5\% strongly disagreed $(\mathrm{M}=4.44, \mathrm{SD}=1.038)$. Whether there were opportunities to improvise, $63 \%$ strongly agreed, and $21 \%$ mildly agreed. About $8 \%$ agreed and $7 \%$ either mildly or strongly disagreed $(\mathrm{M}=4.33, \mathrm{SD}=$ 1.120). The majority of participants strongly agreed that personnel in need of the exercise participated $(55 \%)$, while $27 \%$ mildly agreed. About 6\% strongly disagreed that personnel who needed it participated in the exercise $(\mathrm{M}=$ $4.31, \mathrm{SD}=1.124)$. In total, $59 \%$ of the participants strongly believed that they performed well-known activities, while $27 \%$ mildly agreed. Only $8 \%$ disagreed $(\mathrm{M}=4.31, \mathrm{SD}=$ 1.089). In total, $91 \%$ agreed that collaboration was initiated immediately, while only $7 \%$ strongly disagreed $(\mathrm{M}=4.29$, $\mathrm{SD}=1.192)$. When asked whether clear instructions on collaboration were presented, 64\% strongly agreed, while $22 \%$ mildly agreed. Only $10 \%$ disagreed $(\mathrm{M}=4.38, \mathrm{SD}=$ 1.052). Half of the participants strongly agreed that their points of view were regarded, while only $8 \%$ disagreed $(\mathrm{M}$ $=4.21, \mathrm{SD}=1.052$ ). The overall mean of collaboration was 4.317, while SD was 0.954.

\subsection{Learning}

Most of the respondents either strongly (71.0\%) or mildly (19\%) agreed that they had learned new things during the exercise $(\mathrm{M}=4.48, \mathrm{SD}=1.049)$. If the exercise participants felt that they had learned about others' organizational aspects, $2 \%$ mildly disagreed while $6 \%$ strongly disagreed. A total of $87 \%$ either strongly $(68 \%)$ or mildly $(19 \%)$ agreed to the statement $(\mathrm{M}=4.38, \mathrm{SD}=1.170)$. In total, $75 \%$ either strongly or mildly agreed that they had learned how others prioritize their activities $(\mathrm{M}=4.31$, SD $=1.178)$, while more than two-thirds $(86 \%)$ had learned about the communication patterns of others. Here, $7 \%$ remained neutral $(\mathrm{M}=4.40, \mathrm{SD}=1.082)$. Eighty-six out of 100 participants agreed, while six participants disagreed to learning new concepts and abbreviations $(\mathrm{M}=4.36, \mathrm{SD}=$ 1.142). The general mean for learning was 4.406 , while the SD summed up to 1.031 .

\subsection{Utility}

Most of the participants (88\%) found the exercise useful for real-life activities. Only $7 \%$ disagreed that the exercise was useful $(\mathrm{M}=4.41, \mathrm{SD}=1.083)$. While $8 \%$ disagreed and $3 \%$ remained neutral that the exercise was useful for commanding officers, $88 \%$ agreed to it $(\mathrm{M}=4.34$, SD $=1.157)$. More than half of the population $(63 \%)$ strongly agreed that the exercises were useful for ordinary operative staff. Here, only $5 \%$ remained neutral $(\mathrm{M}=4.39, \mathrm{SD}=$ 1.034). Finally, $88 \%$ agreed that the exercise experience would affect their daily work, while $4 \%$ remained neutral, and $8 \%$ disagreed $(\mathrm{M}=4.39, \mathrm{SD}=1.081)$. The overall mean for the utility was 4.399 , while the standard deviation was 1.032 .

Overall means and standard deviations of collaboration, learning, and usefulness are outlined in Table 2.

\subsection{Bivariate Analysis}

The authors used the bivariate analysis to determine the relationship between the variables of collaboration exercises and learning, and between learning and usefulness.

\subsubsection{The Relationship between Collaboration Exercises and Learning}

Bivariate analysis (Table 3): The significant relationship was between learning and the item "The exercises were focused on collaboration" ( $r=0.877, r^{2}=0.767, \mathrm{~F}=$ 316.307, $\mathrm{p} \leq 0.000$ ), while "Sufficient forms of discussion were provided" had a $r$-value of $0.752\left(r^{2}=0.561, \mathrm{~F}=\right.$ 123.641, $\mathrm{p} \leq 0.000)$.

The item "There were opportunities to improvise" had significance levels $r=0.776\left(r^{2}=0.598, \mathrm{~F}=142.334, \mathrm{p} \leq\right.$ $0.000)$, and "Personnel in need of exercise participated" followed closely with a significance level of $r=0.738\left(r^{2}=\right.$

Table 2 Mean values of collaboration, learning, and utility (CLU) dimensions

\begin{tabular}{lll}
\hline & Mean values & Standard deviation \\
\hline Collaboration & 4.317 & 0.954 \\
Learning & 4.406 & 1.031 \\
Utility & 4.399 & 1.032 \\
\hline
\end{tabular}


Table 3 Bivariate regression of the collaboration dimensions of learning

Dependent variable: learning

Independent variables: collaboration characteristics of exercises

\begin{tabular}{|c|c|c|c|c|}
\hline & Pearson's $r$ & R-Square & F-Value & Significance $(p)$ \\
\hline The exercises were focused on collaboration & 0.877 & 0.767 & 316.307 & 0.000 \\
\hline Sufficient forms of discussion were provided & 0.752 & 0.561 & 123.641 & 0.000 \\
\hline There were opportunities to improvise. & 0.776 & 0.598 & 142.334 & 0.000 \\
\hline Personnel in need of exercise participated & 0.738 & 0.540 & 113.869 & 0.000 \\
\hline I performed well-known activities & 0.745 & 0.550 & 118.148 & 0.000 \\
\hline Collaboration was initiated immediately & 0.805 & 0.645 & 173.537 & 0.000 \\
\hline Clear instructions on collaboration were presented & 0.890 & 0.790 & 361.927 & 0.000 \\
\hline My point of view was regarded & 0.717 & 0.509 & 100.440 & 0.000 \\
\hline
\end{tabular}

0.540, $\mathrm{F}=113.869, \mathrm{p} \leq 0.000$. The item "I performed well-known activities" had a $r$-value of $0.745\left(r^{2}=0.550\right.$, $\mathrm{F}=118.148, \mathrm{p} \leq 0.000)$, and "Collaboration was initiated immediately" had a $r$-value of $0.805\left(r^{2}=0.645, \mathrm{~F}=\right.$ 173.537, $\mathrm{p} \leq 0.000)$.

The item "Clear instructions on collaboration were presented" had the strongest relationship with learning, with a $r$-value of $0.890\left(r^{2}=0.790, \mathrm{~F}=361.927, \mathrm{p} \leq\right.$ $0.000)$, and the item "My points of view were regarded" had a $r$-value of $0.717\left(r^{2}=0.509, \mathrm{~F}=100.440, \mathrm{p} \leq 0.000\right)$.

The multivariate analysis results (Table 4 ) show that the relationship between the collaboration dimensions of learning and the variables "The exercises were focused on collaboration" and "Clear instructions about collaboration were presented" were significant. The collaborative characteristics predicted $79.3 \%\left(r^{2=} 0.793\right)$ of the learning variance, meaning that the remaining $20.7 \%$ of the predicted variance was unaccounted. The regression analysis indicated an $89.2 \%(r=0.892)$ covariance between learning and collaboration characteristics. According to Cohen (2013), this is a sufficiently strong covariation.

\subsubsection{The Relationship between Learning and Usefulness}

The bivariate regression results (Table 5) show that the most profound significance was between usefulness and the item "I learned new things during the exercise" ( $r=0.878$, $\left.r^{2}=0.769, \mathrm{~F}=326.812, \mathrm{p} \leq 0.000\right)$, followed by "I learned others' concepts and abbreviations" ( $r=0.875, r^{2}=0.764$, $\mathrm{F}=314.478, \mathrm{p} \leq 0.000)$, and "I learned about others' organizational aspects" ( $r=0.858, r^{2}=0.733, \mathrm{~F}=266.872$, $\mathrm{p} \leq 0.000)$. The item "I learned about others' communication patterns" received a $r$-value of $0.858\left(r^{2}=0.733, \mathrm{~F}=\right.$ 270.429, $\mathrm{p} \leq 0.000)$. The last item was "I learned about others' prioritization of activities" with a $r$-value of 0.828 $\left(r^{2}=0.764, \mathrm{~F}=314.478, \mathrm{p} \leq 0.000\right)$.

Multivariate analysis (Table 6): The perceived learning items predicted $81.1 \%\left(r^{2}=0.811\right)$ of the usefulness variance, meaning that the remaining $18.9 \%$ of the predicted variance was unaccounted. The items that were found to be significant were "I learned new things during the exercise" ( $\mathrm{p}=0.003)$ and "I learned others' concepts and abbreviations" $(\mathrm{p}=0.000)$. These results $(r=91.4 \%)$

Table 4 Multiple regression of the collaboration dimensions of learning

Dependent variable: learning

Independent variables: collaboration characteristics of exercises

\begin{tabular}{|c|c|c|c|}
\hline & Bivariate regression standard beta & Multivariate regression standard beta & Significance (p) \\
\hline The exercises were focused on collaboration & 0.877 & 0.341 & 0.002 \\
\hline Sufficient forms of discussion were provided & 0.752 & -0.009 & 0.919 \\
\hline There were opportunities to improvise & 0.776 & 0.019 & 0.824 \\
\hline Personnel in need of exercise participated & 0.738 & 0.016 & 0.841 \\
\hline I performed well-known activities & 0.745 & 0.000 & 0.996 \\
\hline Collaboration was initiated immediately & 0.805 & 0.120 & 0.201 \\
\hline Clear instructions on collaboration were presented & 0.890 & 0.418 & 0.000 \\
\hline My point of view was regarded & 0.717 & 0.083 & 0.314 \\
\hline
\end{tabular}

$r=0.892, r^{2}=0.793$, Significance $=\mathrm{p}<0.05$ 
Table 5 Bivariate regression of the learning dimensions of usefulness

Dependent variable: utility

Independent variables: learning characteristics of exercises

\begin{tabular}{lllll}
\hline & Pearson's $r$ & R-Square & F-Value & Significance (p) \\
\hline I learned new things during the exercise & 0.878 & 0.769 & 326.812 & 0.000 \\
I learned about others' organizational aspects & 0.858 & 0.733 & 266.872 & 0.000 \\
I learned about others' communication patterns & 0.858 & 0.733 & 270.429 & 0.000 \\
I learned about others' prioritization of activities & 0.828 & 0.683 & 209.812 & 0.000 \\
I learned others' concepts and abbreviations & 0.875 & 0.764 & 314.478 & 0.000 \\
\hline
\end{tabular}

Table 6 Multiple regression of the learning dimensions of usefulness

Dependent variable: utility

Independent variables: learning characteristics of exercises

\begin{tabular}{llcc}
\hline & Bivariate regression Standard beta & Multivariate regression standard beta & Significance (p) \\
\hline I learned new things during the exercise & 0.878 & 0.333 & .003 \\
I learned about others' organizational aspects & 0.858 & 0.239 & .140 \\
I learned about others' communication patterns & 0.859 & -0.006 & .970 \\
I learned about others' prioritization of activities & 0.828 & -0.041 & .730 \\
I learned others' concepts and abbreviations & 0.875 & 0.432 & .000 \\
\hline
\end{tabular}

$r=0.914, r^{2}=0.811$, Significance $=\mathrm{p}<0.05$

indicate a strong relationship between learning and usefulness (Cohen 2013).

\section{Discussion}

In this study, 3LC exercises were conducted for the first time through virtual communication between experts from Sweden and Norway and health practitioners and participants from Saudi Arabia. Although online learning has long been recognized as a practical learning tool (Aronoff et al. 2010), its use can be problematic for students who are used to student-teacher interaction in a classroom environment and may impact student participation and the expression of their opinions (Middleton 1997; Al-Fahad 2009). However, a study by Elfaki et al. (2019) compared the perceptions of a group of nursing students about virtual learning versus traditional education and found that students had a positive attitude towards online education, indicating it is a viable learning method. A recent study indicated the importance of virtual education, highlighting that most health and medical colleges and simulation-based healthcare have developed virtual learning through their platforms and urged educational establishments to do likewise (Tabatabai 2020). Participants were equipped with visual and audio virtual communication tools during this study, and five practitioners with experience in disaster management were trained beforehand in leading the exercise.

A study (Brinjee et al. 2021) conducted in the KSA stated that the nurses with less experience in emergency departments (EDs) had significantly lower levels of disaster management knowledge than those who had spent long periods working in EDs in terms of understanding the incident management systems and its components. Consequently, these authors highly recommended that there must be a disasters course included in nursing curriculums, intensive training courses, mock drills, and simulations (Brinjee et al. 2021). The outcomes of these first virtual 3LC exercises show that the majority of participants strongly agreed that the exercises focused on collaboration, that participants had learned and acquired new knowledge during the exercises, and that the exercises were helpful for real-life activities. There was a statistically significant association between the exercises, collaboration, and learning. The collaboration exercises in this study could be regarded as having improved learning, since the CLU dimensions had a value $\mathrm{M}=4.4$, making the overall effect of the 3LC course satisfactory.

These results may suggest that people perceive collaboration to be essential in day-to-day activities and in solving emerging issues in the workplace (Perry 2004; Magnussen et al. 2018; Sørensen et al. 2018). A relatively high percentage of participants agreed that the exercises 
focused on collaboration and the people who attended needed the exercises in their daily activities, 85 and $82 \%$, respectively. This supports the assumption that exercises motivate people to address interorganizational challenges during significant incidents (Fattah et al. 2012). In addition, collaboration exercises will contribute to providing opportunities to tackle issues in individual organizations that are unable to handle these challenges on their own and need additional personnel collaboration support to help management deal with the adverse outcomes of a crisis (Huxham and Vangen 2005; Berlin and Carlström 2011; Powley and Nissen 2012).

Not engaging sufficient collaboration in times of crisis may affect society's ability to deal with adverse consequences (Sawalha 2014), making it harder for strategic leaders to impose order and meet social expectations (Boin and Bynander 2015). A lack of collaboration may further result in less resilience, flexibility, and efficiency in dealing with disaster situations (Jung and Song 2015). Powley and Nissen (2012) confirmed that collaboration exercises contribute to helping managers and societies to deal successfully with the adverse effects of a crisis. The present findings indicate that clear instructions and ample opportunities for discussion during and after an exercise are important in order to acquire learning. The present study shows that improvising, jointly evaluating, and testing new and alternative strategies among different sectors promote success in the management of emergencies. A major crisis may necessitate a greater emphasis on flexibility, for example, sequential and parallel collaboration. Alexander (2000) argues that, since exercises alone cannot adequately promote emergency management learning, engaging with scenarios bridges the gap between classroom training and practice during actual disasters. Our study's results suggest that collaboration exercises do not depend as much on the task itself, or the elements involved in the exercises, as they do on working together. The essence of the exercises is that each individual with their own professional knowledge is faced with situations and tasks in which they have to adapt and work together with colleagues who have different professional skills and views (Scholtens 2008).

Gredler (1992) reported that learning might be improved if the personnel is given time for discussion and reflection. Only half of the respondents in the present study strongly felt that their views were regarded. Space to allow participants to air their views and consider the network approaches to understanding the significance of bilateral trust between agencies and authorities is therefore essential (Kapucu and Garayev 2011). Exercises are more effective when the practical sessions are held in tandem with open forums and discussions by the participants to incorporate the day-to-day experience of participants into the theoretical education curriculum (Moynihan 2008). Regression analysis showed marginally stronger covariation between the perceived learning and usefulness dimensions, than between the collaboration and learning dimensions of the exercises. This suggests that participants related their learning to real-life events (Drennan and McConnell 2007).

This study emphasizes the usefulness of virtual exercises and the importance of collaboration exercises. Working together in crisis management enhances the perceived utility of exercises in real accident work, develops the ability to change strategies based on the existing situation, and strengthens attempts to make a safer society.

\section{Limitations}

Even though our results were largely significant, the study was limited in terms of the scope of data collected. The data were only collected from a small number of participants. This constraint reduces the odds of reaching a reliable conclusion or determining results from which suitable forecasts can be made (Coughlan et al. 2009). According to Eisenhardt and Graebner (2007), this can be mitigated through qualitative methods such as observations and interviews to limit informant bias and increase comprehensive insight. Receiving relatively invalid responses was possible because the meanings of collaboration, learning, and utility may have been ill-defined or misunderstood by the participants. The 3LC course was conducted in Saudi Arabia for the first time and in only one of 13 administrative regions (Najran) of the KSA, which is by no means the most important or populous province. Thus it is not possible to generalize the results of this study to all state agencies and regional societies.

\section{Conclusion}

Previous studies have reported a lack of formal educational resources among KSA nurses and have emphasized the need to engage medical personnel in training courses and simulation exercises on the mitigation, preparedness, and response core competencies of disaster management ( $\mathrm{Al}$ Thobaity et al. 2016). Such requirements might be more difficult to meet in a pandemic. This study confirms the feasibility of three level collaboration exercises conducted virtually. Our work also demonstrates that learning depends on collaboration practices and that collaboration exercises before crises can help to build qualities that people can apply in daily life. Collaboration elements exercised in this study contributed to perceived learning. There was a strong covariation between participation in the participants' collaboration exercises and perceived learning and utility. The virtual three level collaboration exercises 
were well-received by the participants and achieved an acceptable collaboration, learning, and utility score. The results of this study open up the possibility of remote education in disaster management, at least from an organizational perspective, in a world with an increasing number of disasters and public health emergencies (Khorram-Manesh and Burkle 2020).

Acknowledgments We would like to thank all instructors from Saudi Arabia and Sweden (Hadi Al Sulayyim, Mohammed Al-Urfan, Mohammed Lasloum, Hamad Al Grad, and Matthias Johansson) for their help and support in implementing the collaboration, learning, and utility courses.

Open Access This article is licensed under a Creative Commons Attribution 4.0 International License, which permits use, sharing, adaptation, distribution and reproduction in any medium or format, as long as you give appropriate credit to the original author(s) and the source, provide a link to the Creative Commons licence, and indicate if changes were made. The images or other third party material in this article are included in the article's Creative Commons licence, unless indicated otherwise in a credit line to the material. If material is not included in the article's Creative Commons licence and your intended use is not permitted by statutory regulation or exceeds the permitted use, you will need to obtain permission directly from the copyright holder. To view a copy of this licence, visit http://creativecommons. org/licenses/by/4.0/

\section{References}

Alexander, D. 2000. Scenario methodology for teaching principles of emergency management. Disaster Prevention and Management 9(2): 89-97.

Al-Fahad, F.N. 2009. Students' attitudes and perceptions towards the effectiveness of mobile learning in King Saud University, Saudi Arabia. Turkish Online Journal of Educational Technology 8(2): 111-119.

Al Thobaity, A., S. Alamri, V. Plummer, and B. Williams. 2019. Exploring the necessary disaster plan components in Saudi Arabian hospitals. International Journal of Disaster Risk Reduction 41: Article 101316.

Al Thobaity, A., B. Williams, and V. Plummer. 2016. A new scale for disaster nursing core competencies: Development and psychometric testing. Australasian Emergency Nursing Journal 19(1): $11-19$.

Andersson, A., E.D. Carlstrom, B. Ahgren, and J.M. Berlin. 2014. Managing boundaries at the accident scene-A qualitative study of collaboration exercises. International Journal of Emergency Services 3(1): 77-94

Aronoff, S.C., B. Evans, D. Fleece, P. Lyons, L. Kaplan, and R. Rojas. 2010. Integrating evidence based medicine into undergraduate medical education: Combining online instruction with clinical clerkships. Teaching and Learning in Medicine 22(3): 219-223.

Berlin, J.M., and E.D. Carlström. 2008. The 90-second collaboration: A critical study of collaboration exercises at extensive accident sites. Journal of Contingencies and Crisis Management 16(4): $177-185$

Berlin, J.M., and E.D. Carlström. 2008. The 20-minute team-A critical case study from the emergency room. Journal of Evaluation in Clinical Practice 14(4): 569-576.
Berlin, J.M., and E.D. Carlström. 2011. Why is collaboration minimized at the accident scene? A critical study of a hidden phenomenon. Disaster Prevention and Management 20(2): 159-171.

Berlin, J.M., and E.D. Carlström. 2015. The three-level collaboration exercise-Impact of learning and usefulness. Journal of Contingencies and Crisis Management 23(4): 257-265.

Boin, A., and F. Bynander. 2015. Explaining success and failure in crisis coordination. Geografiska Annaler Series A Physical Geography 97(1): 123-135.

Boin, A., and P. 't Hart. 2010. Organising for effective emergency management: Lessons from research. Australian Journal of Public Administration 69(4): 357-371.

Brace, N., R. Kemp, and R. Snelgar. 2006. SPSS for psychologists: A guide to data analysis using SPSS for Windows, 3rd edn. Mahwah, NJ: Lawrence Erlbaum Associates Publishers.

Brinjee, D., A. Al Thobaity, M. Almalki, and W. Alahmari. 2021. Identify the disaster nursing training and education needs for nurses in Taif City, Saudi Arabia. Risk Management and Healthcare Policy 14: 2301-2310.

Budd, J., B.S. Miller, E.M. Manning, V. Lampos, M. Zhuang, M. Edelstein, G. Rees, and V.C. Emery et al. 2020. Digital technologies in the public-health response to COVID-19. Nature Medicine 26(8): 1183-1192.

Carter, W.N. 2008. Disaster management: A disaster manager's handbook. Boston: Springer.

Charman, S. 2013. Blue light communities: Cultural interoperability and shared learning between ambulance staff and police officers in emergency response. Policing and Society 24(1): 102-119.

Cohen, J. 2013. Statistical power analysis for the behavioral sciences. Cambridge, MA: Academic Press.

Coppola, D.P. 2006. Introduction to international disaster management. London: Elsevier.

Coughlan, M., P. Cronin, and F. Ryan. 2009. Survey research: Process and limitations. International Journal of Therapy and Rehabilitation 16(1): 9-15.

Drennan, L.T., and A. McConnell. 2007. Risk and crisis management in the public sector. New York: Routledge.

Eisenhardt, K.M., and M.E. Graebner. 2007. Theory building from cases: Opportunities and challenges. Academy of Management Journal 50(1): 25-32.

Elfaki, N.K., I. Abdulraheem, and R. Abdulrahim. 2019. Impact of e-learning vs traditional learning on student's performance and attitude. International Journal of Medical Research \& Health Sciences 8(10): 76-82.

Fattah, S., A. Krüger, J. Andersen, T. Vigerust, and M. Rehn. 2012. Major incident preparedness and on-site work among Norwegian rescue personnel-A cross-sectional study. International Journal of Emergency Medicine 5(40): 1-7.

Gredler, M.E. 1992. Designing and evaluating games and simulations: A process approach. Houston: Gulf Professional Publishing.

Huxham, C., and S. Vangen. 2005. Managing to collaborate - The theory and practice of collaborative advantage. London: Routledge.

Jung, K., and M. Song. 2015. Linking emergency management networks to disaster resilience: Bonding and bridging strategy in hierarchical or horizontal collaboration networks. Quality \& Quantity 49(4): 1465-1483.

Kapucu, N., and V. Garayev. 2011. Collaborative decision-making in emergency and disaster management. International Journal of Public Administration 34(6): 366-375.

Khorram-Manesh, A. 2020. Flexible surge capacity-public health, public education, and disaster management. Health Promotion Perspectives 10(3): Article 175. 
Khorram-Manesh, A., and F.M. Burkle. 2020. Disasters and public health emergencies-Current perspectives in preparedness and response. Sustainability 12(20): Article 8561.

Khorram-Manesh, A., M. Ashkenazi, A. Djalali, P.L. Ingrassia, T. Friedl, G. von Armin, O. Lupesco, and K. Kaptan et al. 2015. Education in disaster management and emergencies: Defining a new European course. Disaster Medicine and Public Health Preparedness 9(3): 245-255.

Khorram-Manesh, A., J. Berlin, and E. Carlstrom. 2016. Two validated ways of improving the ability of decision-making in emergencies; Results from a literature review. Bulletin of Emergency \& Trauma 4(4): 186-196.

Khorram-Manesh, A., O. Lupesco, T. Friedl, G. Arnim, K. Kaptan, A.R. Djalali, M. Foletti, and P.L. Ingrasia et al. 2016. Education in disaster management: What do we offer and what do we need? Proposing a new global program. Disaster Medicine and Public Health Preparedness 10(6): 854-873.

Klabbers, J.H.G. 1999. Three easy pieces: A taxonomy on gaming. In Simulations and games for strategy and policy planning, simulation and gaming yearbook, vol. 7, ed. D. Saunders, and J. Severn. London: Kogan.

Magnussen, L.I., E. Carlstrøm, J.L. Sørensen, G.E. Torgersen, E.F. Hagenes, and E. Kristiansen. 2018. Learning and usefulness stemming from collaboration in a maritime crisis management exercise in Northern Norway. Disaster Prevention and Management 27(1): 129-140.

Mani, Z.A., L. Kuhn, and V. Plummer. 2020. Common domains of core competencies for hospital health care providers in armed conflict zones: A systematic scoping review. Prehospital and Disaster Medicine 35(4): 442-446.

Middleton, A.J. 1997. How effective is distance education? International Journal of Instructional Media 24(2): Article 133.

Moynihan, D.P. 2008. Learning under uncertainty: Networks in crisis management. Public Administration Review 68(2): 350-365.

Oktari, R.S., K. Munadi, and R. Idroes. 2020. Knowledge management practices in disaster management: Systematic review. International Journal of Disaster Risk Reduction 51(2): Article 101881.

Perry, R.W. 2004. Disaster exercise outcomes for professional emergency personnel and citizen volunteers. Journal of Contingencies and Crisis Management 12(2): 64-75.

Powley, E.H., and M.E. Nissen. 2012. If you can't trust, stick to hierarchy: Structure and trust as contingency factors in threat assessment contexts. Journal of Homeland Security and Emergency Management 9(1): Article 14.

Raosoft. 2004. Raosoft sample size calculator. http://www.raosoft. com/samplesize.html. Accessed 14 Oct 2021.

Revell, A., and E. Wainwright. 2009. What makes lectures "unmissable"? Insights into teaching excellence and active learning. Journal of Geography in Higher Education 33(2): 209-223.

Roud, E., and A.H. Gausdal. 2019. Trust and emergency management: Experiences from the Arctic Sea region. Journal of Trust Research 9(2): 203-225.
Sagun, A., D. Bouchlaghem, and C.J. Anumba. 2009. A scenariobased study on information flow and collaboration patterns in disaster management. Disasters 33(2): 214-238.

Sahu, P. 2020. Closure of universities due to coronavirus disease 2019 (COVID-19): Impact on education and mental health of students and academic staff. Cureus 12(4): Article e7541.

Sawalha, I.H.S. 2014. Collaboration in crisis and emergency management: Identifying the gaps in the case of storm "Alexa". Journal of Business Continuity \& Emergency Planning 7(4): 312-323.

Scholtens, A. 2008. Controlled Collaboration in disaster and crisis management in the Netherlands, history and practice of an overestimated and underestimated concept. Journal of Contingency and Management 16(4): 195-207.

Schwartzstein, R.M., and D.H. Roberts. 2017. Saying goodbye to lectures in medical school-Paradigm shift or passing fad. New England Journal of Medicine 377(7): 605-607.

Sørensen, J.L., C. Halvorsen, J.P.W Aas, and E. Carlström. 2020. "Share your tools"-A utility study of a Norwegian wildlandfire collaboration exercise. Sustainability 12(16): Article 6512.

Sørensen, J.L., L.I. Magnussen, G.E. Torgersen, A.M. Christiansen, and E. Carlström. 2018. Perceived usefulness of maritime crossborder collaboration exercises. Arts and Social Sciences Journal 9(4): $1-5$.

Spiceland, D., and C. Hawkins. 2002. The impact on learning of an asynchronous active learning course. Journal of Asynchronous Learning Networks 6(1): 68-75.

Stein, J. 1997. How institutions learn: A socio-cognitive perspective. Journal of Economic Issues 31(3): 729-740.

Sultan, M.A.S., A. Khorram-Manesh, E. Carlström, J.L. Sørensen, H.J.A. Sulayyim, and F. Taube. 2020a. Nurses' readiness for emergencies and public health challenges-The case of Saudi Arabia. Sustainability 12(19): Article 7874.

Sultan, M.A.S., J.L. Sørensen, E. Carlström, L. Mortelmans, and A. Khorram-Manesh. 2020b. Emergency healthcare providers' perceptions of preparedness and willingness to work during disasters and public health emergencies. Healthcare 8(4): Article 442.

Tabatabai, S. 2020. Simulations and virtual learning supporting clinical education during the COVID 19 pandemic. Advances in Medical Education and Practice 11: 513-516.

Torani, S., P.M. Majd, S.S. Maroufi, M. Dowlati, and R.A. Sheikhi. 2019. The importance of education on disasters and emergencies: A review article. Journal of Education and Health Promotion 8: 85-94.

WHO (World Health Organization). 2017. A strategic framework for emergency preparedness. https://apps.who.int/iris/bitstream/han dle/10665/254883/9789241511827-eng.pdf;jsessionid= F17E52C654D50ADCB045E8F3922AF62D?sequence=1. Accessed 4 Feb 2021.

WHO (World Health Organization). 2021. Risk communication simulation exercises. https://www.who.int/emergencies/risk-com munications/simulation-exercises. Accessed 18 Feb 2021. 